\title{
TUDO QUE RELUZ É OURO?: PERFORMATIVIDADE E EDUCAÇÃO FÍSICA ESCOLAR
}

\author{
TODO LO QUE LA LUZ ES ORO: PERFORMATIVIDAD \\ Y EDUCACIÓN FÍSICA ESCOLAR
}

\section{EVERYTHING THAT LIGHT IS GOLD?: PERFORMATIVITY AND SCHOOL PHYSICAL EDUCATION}

\author{
JEDERSON GARBIN TENÓRIO \\ IRede de Ensino Público de Mato Grosso/MT-Brasil
}

RESUMO Este estudo pretende explicitar elementos presentes na prática metodológica da Educação Física (EF) escolar que representam a busca pela produtividade e desempenho, expostos em indicadores quantitativos, como resultados obtidos em competições escolares. As aulas de EF, ao se basearem no esporte de alto nível, caracterizam-se pelas equipes formadas para disputa de campeonatos, medalhas que conquistam etc. Como metodologia realizamos uma revisão bibliográfica, denotando um estudo qualitativo. Consideramos que maneiras sutis e eficazes de controle do trabalho do professor de EF são moldadas em função do esporte de alto nível, servindo como uma espécie de ranking, subsidiando educadores, gestores e políticas públicas.

Palavras-Chave: EducaÇão física escolar; Competições escolares; Performatividade.

ABSTRaCT This study intends to make explicit elements present in the methodological practice of Physical Education (PE) at school, which represent the search for productivity and performance, presented in quantitative indicators, such as, results obtained in school competitions. EF classes, based on high-level sport, are characterized by teams formed to compete in championships, medals that win etc. As a methodology, we performed a bibliographic review, characterizing a qualitative study. We consider that subtle and effective ways of controlling EF teacher work are shaped by high-level sport, serving as a kind of ranking, subsidizing educators, managers, and public policy.

Key-words: Physical school education; School competitions; Performativity. 
RESUMEN Este estudio pretende explicitar elementos presentes en la práctica metodologica de la Educación Física (EF) escolar que representan la búsqueda por la productividad y desempeño, expuestos en indicadores cuantitativos, tales como resultados obtenidos en competencias escolares. Las clases de EF, al basarse en el deporte de alto nivel, se caracterizan por los equipos formados para la disputa de campeonatos, medallas que conquistan, etc. Como metodología realizamos una revisión bibliográfica, caracterizando un estudio cualitativo. Consideramos que las maneras sutiles y eficaces de control del trabajo del profesor de EF se moldean en función del deporte de alto nivel, sirviendo como una especie de ranking, subsidiando a educadores, gestores y políticas públicas.

Palabras Clave: Educación física escolar; Competiciones escolares; Performatividad.

\section{INTRODUÇ̃̃̃o}

Ao longo de muitos anos, as aulas de EF privilegiavam a busca pela melhoria da condição física dos sujeitos, ancorada sob a lógica das Ciências Biológicas, valorizando o conhecimento prático, além de exercícios ginásticos repetitivos e a execução de movimentos de maneira padronizada.

Para Daolio (2006), a forte presença do evolucionismo de Darwin do século XIX influenciava as Ciências Naturais no século XX, que desconsiderava as diferenças entre os seres humanos, concebendo os homens do ponto de vista de suas semelhanças físicas, sendo explicadas naturalmente, determinadas pelas propriedades biológicas dos indivíduos. Na observação do autor, os europeus eram considerados os povos mais civilizados e, portanto, dotados de cultura. Outros povos distantes eram vistos como primitivos, que, na visão europeia, ainda não tinham atingido características da civilização desse continente. Esse pensamento, concebia também os seres humanos como um amontoado de ossos, músculos, células e articulações, ou seja, a importância dada aos aspectos anátomo-fisiológicos dos sujeitos, era o entendimento mais valorizado para se referir aos diversos indivíduos.

A lógica da Ciência Moderna, em estreita relação com as Ciências Naturais, que valoriza os aspectos quantitativos, explicações objetivas, evidenciadas por meio de fórmulas e números, rivaliza com as Ciências Humanas e Sociais em que o conhecimento é oriundo de pesquisas de campo, inserções no contexto investigado e observações sistemáticas, são construções teóricas interpretativas e subjetivas, que buscam compreender os fenômenos na sua totalidade (BARBOSA, 2011).

Essa distinção entre aspectos biológicos e culturais é parte de concepções e conhecimentos construídos ao longo da história. "Em nossa área, o tradicional termo educação física traz embutido o significado de uma oposição entre natureza e cultura; ou, em outros termos, entre o inato e o adquirido" (DAOLIO, 2006, p. 63).

No Brasil, a EF foi inserida na escola no final ${ }^{1}$ do século XIX e, até meados da década de 1940, era considerada sob a forma de ginástica. As instituições militares, médicas e

1 Em 1882, Rui Barbosa, na condição de deputado, propôs uma reforma do ensino sob o "Parecer sobre Ensino Secundário e Superior", em que foram inseridos conteúdos como a ginástica, o desenho, a música e o ensino de ciências nas escolas de ensino básico (MORMUL e MACHADO, 2013). Nesse sentido, a introdução de uma "disciplina" específica ligada a atividades físicas na escola, no Brasil, está inserida nesse contexto. 
desportivas, ao longo do século XX, tiveram grande influência nas aulas. As mesmas eram ministradas por instrutores do exército e a disciplina era tida também como EF militar (BRACHT, 1992).

As aulas associadas aos exercícios ginásticos "privilegia(va)m" a execução de movimentos repetitivos, que buscavam promover nos alunos um nível de aptidão física, classificando-os em aptos e inaptos. "A Educação Física sempre fez um discurso, baseado nas Ciências Naturais, de controle do corpo, de "construção" de um corpo saudável e produtivo, treinável e capaz de grandes e belos desempenhos motores" (BRACHT, 1999, p. 54). Posteriormente, com o fim da Segunda Guerra Mundial, em 1945, a adoção do esporte como conteúdo nas aulas, começou a tomar como predominante esse elemento da cultura corporal de movimento em várias partes do mundo.

Esse movimento, que teve como foco as aulas de EF, fez que o esporte fosse adotado como conteúdo privilegiado nas aulas devido à sua importância social e política. Nesse contexto, a finalidade principal era garantir a eficiência do sistema esportivo e a EF compreendida, restritamente, como esporte, tendo como foco o ensino das técnicas esportivas. Concomitante a esse movimento, a partir da segunda metade do século XX, ocorre no país, uma ampliação ${ }^{2}$ do número de vagas na educação básica, que evidenciava formas qualitativas de expandir a escolarização, que começou ganhar força com o processo de urbanização e industrialização no país. Dessa maneira, o Estado adota "[...] um ethos competitivo, neodarwinista, passando a admitir a lógica do mercado, através da importação para o domínio público de modelos de gestão privada, com ênfase nos resultados ou produtos dos sistemas educativos" (AFONSO, 2009, p. 49). Nesse sentido, o esporte representa(va) um exemplo clássico de desempenho e rendimento que era tido como a própria $\mathrm{EF}$, ganhando mais espaço na década de 1970, sendo ditado o "ritmo do jogo" pelo sistema social e político, cabendo à escola apenas "seguir a cartilha" de governos, federações e clubes.

Dessa forma, percebemos em nosso campo de atuação, alguns dispositivos que influenciam a prática pedagógica, cabendo a nós construirmos uma reflexão que nos possibilite "superar-compreender" comportamentos que são adotados no trabalho docente.

Isso porque, nosso entendimento é balizado pela compreensão que a aula de EF deve ser um espaço que tenha na cultura corporal de movimento, conteúdos que sejam explorados e oportunizados aos alunos, que possuem expectativas e anseios em relação às aulas e, portanto, nem sempre o esporte alcançará esse objetivo, devendo ser pensado e planejado conforme os contextos específicos ao longo do processo de ensino-aprendizagem. Sendo assim, esse estudo, encontra eco nas palavras de Minayo (2001, p. 17): “[...] nada pode ser intelectualmente um problema, se não tiver sido, em primeiro lugar, um problema da vida prática".

Além disso, a EF, como nenhuma área do conhecimento escolar, sofre influência externa da sociedade, por equivocadamente, existir uma compreensão de que os conhecimentos que circulam na mídia na esfera física-esportiva, devam ser reproduzidos nas aulas. Segundo Millen Netto et. al. (2010): “[...] é comum que alunos, a comunidade escolar e, por vezes, os seus professores vejam a Educação Física como uma disciplina exclusivamente

2 Para Marchelli (2010), à partir da década de 1990, em função da democratização do acesso ao Ensino Fundamental no Brasil, as famílias foram obrigadas a matricular os filhos e a escola teve que acolher uma diversidade de alunos e ao mesmo tempo, promover um ensino de qualidade. 
prática e, muitas vezes, voltada para os interesses imediatos dos alunos (como exemplo, o jogar futebol)".

Portanto, o problema fundamental desse estudo, consiste em analisar como se evidencia a cultura da performatividade ${ }^{3}$ na prática pedagógica da EF escolar, como exigência implícita na prática pedagógica do professor.

\title{
Percurso metodológico
}

Como procedimento metodológico foi realizada revisão de literatura caracterizando um tipo de análise que corresponde às pesquisas qualitativas. Para Minayo (1994, p. 21-2), esse tipo de pesquisa:

\begin{abstract}
(...) responde a questões muito particulares. Ela se preocupa, nas ciências sociais, com o nível de realidade que não pode ser qualificado. Ou seja, ela trabalha com o universo de significados, motivos, aspirações, crenças, valores e atitudes, o que corresponde a um espaço mais profundo das relações, dos processos e dos fenômenos que não podem ser reduzidos à operacionalização de variáveis.
\end{abstract}

Ao que se refere ao tratamento das obras que foram referência para este trabalho, tivemos como base as diretrizes para leitura, análise e interpretação de textos, de acordo com Severino (2007):

1. Análise textual, que consistiu em buscar informações a respeito do autor do texto e verificar o vocabulário, os fatos históricos apresentados pelo texto, com a possibilidade de exibir uma esquematização do mesmo, a fim de propiciar uma visão de conjunto da unidade;

2. Análise temática que procurou ouvir o autor e apreender, sem intervir no conteúdo da mensagem apresentada pelo autor, fazendo ao texto uma série de perguntas, sendo que as respostas fornecem o conteúdo da mensagem;

3. Análise interpretativa, em que se busca uma compreensão interpretativa das ideias apresentadas pelo autor. Nesse tipo de análise, compreende-se também a crítica, a formulação de um juízo crítico, de tomada de posição;

4. A problematização, que se trata de um tipo de abordagem com vistas ao levantamento dos problemas para a discussão;

5. A quinta e última etapa trata-se da síntese pessoal, da construção lógica de uma redação, de modo a dar condições ao estudioso de progredir no desenvolvimento das ideias do autor.

O levantamento teórico sobre os temas (juntos e separados): "EF escolar", "competições escolares" e "performatividade" foi realizado a partir da base de dados Scielo, do BDTD e do google acadêmico, sendo consultados periódicos, livros e teses relacionadas aos temas. Pretendíamos, assim, procurar dados abrangentes que pudessem nos

3 "A performatividade é uma tecnologia, uma cultura e um método de regulamentação que emprega julgamentos, comparações e demonstrações como meio de controle, atrito e mudança" (BALL, 2005, p. 543). $\mathrm{Na}$ Educação, essa estratégia é evidenciada quando se adotam elementos no trabalho docente que limitam a capacidade do educador, ser sujeito de sua ação. 
levar a compreender o fenômeno em toda sua complexidade. Primeiramente, buscamos o termo "performatividade" no google acadêmico que nos trouxe como resultado o total de $12.800^{4}$ documentos, sendo selecionados cinco artigos para leitura, que nortearam a discussão e análise dos dados. Nessa mesma home page, pesquisamos os termos: "Educação Física escolar" e "competições escolares", selecionando oito artigos que dialogavam com a palavra performatividade e esporte. No site da BDTD fizemos a busca com a palavra "Performatividade" sozinha e com os demais termos, não encontrando estudos relacionados com os propósitos de nossa discussão. Assim sendo, inserimos as palavras juntas: "Educação Física escolar" e "Competições escolares", tendo 83 arquivos como resultado. Selecionamos então, três teses que foram utilizadas neste texto. Os livros que nos subsidiaram, às vezes não trouxeram o termo de maneira explícita, mas foi preciso um esforço de aproximação com os propósitos do tema, referenciado em Harvey (2008), Daolio (2006), Bracht (2005), entre outros.

Pela própria natureza do tema, nos esforçamos em propor um diálogo entre EF escolar em interface com a performatividade e as competições escolares, considerando que a produção teórica existente, ainda é incipiente. Como nos dizia Paulo Freire (2016, p. 30): "Daí que seja tão fundamental conhecer o conhecimento existente quanto saber que estamos abertos e aptos à produção do conhecimento ainda não existente".

O levantamento bibliográfico ocorreu do mês de novembro de 2018 ao mês de fevereiro de 2019, bem como, a análise que se estendeu até o período de junho de 2019.

\section{O ESPORTE, A EDUCAÇÃo FísiCa ESCOLAR E A PERFORMATIVIDAdE}

O fenômeno esportivo trata-se de uma constituição moderna, que tem sua gênese construída na contemporaneidade, se consolidando, no último século, como importante manifestação que desenvolveu seus valores e ideais em várias partes do mundo. Como defende Bracht (2005, p. 13):

\footnotetext{
O esporte moderno resultou de um processo de modificação, poderíamos dizer, de esportivização de elementos da cultural corporal de movimento das classes populares inglesas, como os jogos populares, cujos exemplos mais citados são os inúmeros jogos com bola, e também, de elementos da cultura corporal de movimento da nobreza inglesa. Este processo inicia-se em meados do século XVIII e se intensifica no final do século XIX e início do XX.
}

Um fator muito significativo, que contribuiu para o seu crescimento foi o movimento olímpico do século XX, que promoveu o esporte à categoria de nação. Ou seja, os resultados obtidos nas competições esportivas, com destaque para as Olimpíadas, começaram a despertar o interesse de grandes países, que os utilizavam para representar seu sistema político (BRACHT, 2005). Nesse sentido, após o final da Segunda Guerra Mundial, sob influência europeia e dos Estados Unidos, o esporte vai se propagando em muitos países do mundo, utilizado como elemento implícito da Guerra Fria e predominante na cultura corpo-

4 Foi comum encontrar a palavra associada a questões de gênero e esporte, se distanciando de nossa discussão que propõe um olhar sobre o controle do trabalho docente. 
ral de movimento. "O esporte sofre no período do pós-guerra um grande desenvolvimento quantitativo” (BRACHT, 1992, p. 22).

Tais entendimentos podem ser compreendidos pelo modo que o esporte faz parte do cotidiano das pessoas e o grande espaço que ele ocupa a nível mundial. Muitas pessoas assistem, leem, conversam e até opinam sobre o assunto, interagindo com esse tema de maneira frequente em seu cotidiano. De acordo com Cruz de Oliveira (2010, p.142): "[...] todo o privilégio de tematização que o esporte recebe na sociedade contemporânea acaba por refletir na EF escolar, pois em nenhuma outra disciplina escolar tal conhecimento é abordado".

O esporte é uma manifestação cultural capaz de mobilizar pessoas do mundo inteiro, tendo imagens e signos capazes de construir uma "padronização cultural"5 que torna a cultura corporal de movimento, quase que subordinada aos seus códigos e seu desempenho.

Isto acontece porque o sistema esportivo somente apela para a categoria educação como forma de buscar legitimidade social. Estando, no entanto, orientado por outros princípios, permanece a questão educacional apenas como recurso retórico (BRACHT, 2005, p.22).

Para Bracht (2005), o esporte é regido por regras facilmente compreendidas, possui uma linguagem simplificada, oferece à população uma identificação com o coletivo e cria ao espectador um ambiente que compensa o tempo de trabalho, trazendo um sentimento de satisfação e divertimento.

O esporte é uma manifestação cultural que reflete o modo como se insere na sociedade, influenciado por interesses capitalistas, sendo relevante a compreensão de como se dá essa relação e penetração dentro da escola.

Para Tubino (2010), o esporte se classifica de três maneiras: a) Esporte-Educação (busca a inclusão e participação de jovens na prática esportiva, compreendendo também competições entre escolas); b) o Esporte-Lazer (as regras podem ser adaptadas e criadas em função do contexto, visando a participação de grande número de pessoas, em busca de saúde e satisfação do praticante) e c) o Esporte-Desempenho (praticado conforme códigos e regras estabelecidos por entidades internacionais. Objetiva vitórias, recordes, títulos, projeções e prêmios financeiros).

Vale destacar que o modelo esportivo utilizado na escola parece se basear no esporte de alto rendimento, encontrando nas competições escolares um meio e fim de compreender as aulas.

A escola foi utilizada como local de descoberta do talento esportivo, principalmente após a década de 1960. "A dimensão quantitativa de esporte parece ser razão suficiente para que a escola assuma este elemento da cultura" (BRACHT, 1992, p.46). Tal elemento da cultura foi ocupando um espaço destacado nesse local e também em outros setores da sociedade.

O esporte não exige mais exercício de legitimação. A Ed. Física esportivizada justifica-se pelo esporte e este por si só na sociedade. Por si só? O Esporte mobiliza recursos, vincula-se à Indústria Cultural e de bens de consumo, que a Ed. Física vai auxiliar a reproduzir (BRACHT, 1992, p.53).

5 Termo considerado por Gomes (2008) simbolizando os mecanismos que a cultura dominante utiliza para concretizar objetivos ligados ao consumo e à consequente obtenção de lucros. O esporte, na contemporaneidade, representa formas dominantes de práticas corporais, que valorizam algumas modalidades esportivas, por meio de códigos, técnicas e estratégias de marketing mais atrativas e eficientes. 
Dessa forma, as influências que adentravam a escola permeavam as aulas de EF, que reproduziam todos esses rituais e modelos esportivos, e o professor de EF era visto com "bons olhos", conforme sua performatividade. "Utilizando uma linguagem sistêmica, poder-se-ia dizer que a influência do meio ambiente (esporte) não foi/é selecionada (filtrada) por um código próprio da Educação Física, o que demonstra sua falta de autonomia na determinação do sentido das ações em seu interior" (BRACHT, 1992, p. 22).

Sendo assim, nada mais simples que atingir reconhecimento profissional agregando competições esportivas estudantis à aula de EF, participando de eventos, ${ }^{6}$ como: Jogos estudantis, Jogos escolares ou Olimpíadas Escolares. Essas competições escolares tornaram-se uma ferramenta muito eficaz de desenvolvimento esportivo dentro da escola como maneira de penetração do esporte baseado no modelo federado, podendo ser visualizada também como incentivo do Estado, em fomentar a participação de escolas de todo o país.

As aulas, ao atenderem novamente aos discursos políticos semelhantes aos da década de 1960 e 1970 ("Brasil-Grande"), coloca o esporte como objeto utilizado pelo governo, para explorá-lo como propaganda política. Para Costa (2015, p. 73): “Os primeiros Jogos Estudantis Brasileiros ocorreram em 1969, por iniciativa do Ministério da Educação e Cultura, na cidade de Niterói, no Rio de Janeiro, e contaram com a participação de sete estados, representados por 315 estudantes".

A partir do ano de 2000, o Ministério do Esporte, o Ministério da Educação e o Comitê Olímpico Brasileiro em parceria com a Rede Globo de Televisão arquitetaram a realização da $1^{a}$ Olimpíada Colegial "Esperança". "Desde então, as competições escolares fazem parte do calendário esportivo das Olimpíadas Escolares, que tem etapas seletivas municipais e estaduais classificatórias para as competições nacionais" (FRIZZO, 2013, p. 166).

Segundo Costa (2015), atualmente as Olimpíadas Escolares agregam a participação de equipes escolares que "podem" participar das fases municipais, estaduais e nacionais.

Ao longo das últimas décadas, as competições escolares, refletem resultados esportivos que os professores alcançam com a formação de equipes, trazendo ao "professor-técnico" certa notoriedade na comunidade escolar e na própria sociedade, mesmo que esse trabalho fosse restrito a poucos "alunos-atletas", pela ótica da "aula-treino". Essa busca por destaque é movida, conforme Harvey (2008), devido à imagem ser um símbolo a ser cultivado para concorrência, na busca por poder, servindo para estabelecer uma identidade, sendo parte integrante de autorrealização e, significado na vida dos sujeitos.

A presença do treinamento nas aulas e o planejamento voltado às finalidades de participação nas competições esportivas, são destacados por Souza, Rezende e Oliveira (2011), que nos esclarecem que as aulas podem estar servindo de treinamento para um número limitado de alunos, enquanto outros (os que mais necessitam) ficam em segundo plano.

6 Para o presente trabalho, não diferenciamos os termos, por entendermos que ambos possuem as mesmas finalidades e características.

7 Slogan utilizado pelo regime militar do Governo Médici, que visava propagar a ideia de ascensão política e econômica, que faria o país uma grande potência. Ao mesmo tempo, esse slogan pretendia desviar a atenção política da população devido ao momento de Ditadura Militar que o país atravessava e produzir um sentimento de identificação nacional, por meio do esporte.

8 Termo associado ao Projeto Criança Esperança, da Rede Globo, emissora que teve papel na divulgação dos eventos competitivos escolares a nível regional e nacional. 
As Olimpíadas Escolares correspondem a uma ferramenta eficiente e abrangente do sistema esportivo visto à grande participação $0^{9}$ de Estados e munícipios em edições dos JEB`s que correspondem ao período de 2005 a 2014. Para Bracht (2005, p. 86):

[...] hoje existe uma enorme dificuldade de superar o modelo da pirâmide, que coloca como coroamento do esporte a obtenção de resultados internacionais (estaduais ou municipais) expressivos, porque é dessa forma que o retorno em termos de capital simbólico, traduzível em capital político, para o sistema político, se efetiva.

As competições escolares, ao reproduzirem o esporte de alto nível, possuem capacidade de estabelecer uma relação, via EF escolar e mídia, com um grande número de receptores, espectadores e consumidores, que poderão adotar uma atitude quase sempre passiva em seu tempo disponível do esporte e dos muitos produtos que o mesmo oferece.

Analisando esses dados, partimos para uma aproximação entre a EF escolar e o contexto global, considerando que as relações construídas entre as esferas sociais produzem efeitos nas aulas e na aprendizagem. De acordo com Barbosa (2011, p. 34): "[...] o ensino da educação física não é um fato isolado, e por mais que ela fosse assim (como fato destacado de seu contexto) não se chegaria a uma compreensão (visão total) do problema". Segundo o referido autor, a EF está inserida no Estado e na organização econômica em destaque.

Uma das características do mundo contemporâneo é traduzida na queda de barreiras geográficas que produzem padrões a serem seguidos em diversas partes do mundo. Para Harvey (2008), a compressão do tempo e do espaço conduz a uma intensificação do trabalho e da produção, tornando-se um trunfo no mundo competitivo entre localidades, cidades, regiões e nações. Os padrões produzidos pela sociedade na contemporaneidade causam uma busca pela identidade de modelos predominantes e que mais se destacam em um contexto global.

As aulas de EF têm no esporte a prática corporal que melhor dialoga com o mercado capitalista, como o uso de técnicas, de rendimento, de códigos, e de especificidades de sua atuação. Ou seja, os esportes tradicionais, os campeonatos transmitidos para bilhões de telespectadores, os atletas famosos tornam-se modelos ${ }^{10}$ a serem seguidos por pessoas de várias partes do mundo. Daolio (2006, p. 87) compreende que: “[...] por um lado, há uma tradição cultural que faz com que a educação física seja biológica e universalizante, excluindo muitos alunos; mas, por outro lado, justamente por ser assim ela é conhecida e valorizada".

Nesse sentido, a obtenção de resultados $\left(1^{\circ}\right.$., $2^{\circ}$. e $3^{\circ}$. lugar) colabora para que exista, de forma explícita, uma espécie de ranking entre escolas e professores. Assim, podemos fazer uma comparação dos índices a serem alcançados pelas escolas, ao considerar aquilo que Harvey (2008) nos esclarece, ao destacar que os signos e as imagens são mais valiosos do que a própria mercadoria (aprendizagem).

9 Para Kiouranis (2017, p.212): “[...] a estimativa em relação à participação dos estados em modalidades coletivas mostra que há uma participação intensa dos estados". Ou seja, as etapas municipais e regionais também contam com um número ainda maior de equipes escolares participantes.

10 Mauss (2003) utiliza a expressão "imitação prestigiosa" para se referir aos gestos técnicos de atletas famosos que tornam referência para crianças que os veem com certa autoridade e exercem influência sobre elas. 
Ao preconizar a participação das escolas em competições esportivas, o Estado visa promover comparações quantitativas entre as instituições escolares, assim como faz com os índices de desempenho (IDEB, ${ }^{11}$ Prova Brasil,${ }^{12}$ SAEB ${ }^{13}$ ).

Tais atividades avaliativas ${ }^{14}$ operam no processo de ensino-aprendizagem, compreendidos como ferramentas utilizadas no controle do conteúdo a ser ensinado pelo professor, conforme a lógica do mercado.

\begin{abstract}
Um novo tipo de professor e novos tipos de conhecimentos são “invocados”(...) um professor que consiga maximizar o desempenho, que consiga deixar de lado princípios irrelevantes, ou compromissos sociais fora de moda, para quem a excelência e o aperfeiçoamento sejam a força matriz de sua prática (BALL, 2005 , p. 554, grifos do autor).
\end{abstract}

A existência dessas avaliações colabora para que ocorra um direcionamento de conteúdos pelo órgão governamental, a serem aprendidos, com a finalidade da realização de exames, ou seja, acaba engessando o planejamento docente para atender aos objetivos dessas provas.

O que se quer salientar é que a Educação Física, diga-se escolar, mais uma vez poderá ser legitimada por anseios e funções exógenas a ela, o que dificulta sobremaneira a configuração de sua autonomia pedagógica, pois o discurso por sua persuasão é capaz de seduzir e ganhar os corações e as mentes dos inocentes (GRUNENNVALDT e KUNZ, 2013, p. 25, grifo do autor).

Esses mecanismos criados pelo Estado, que envolvem o trabalho educacional, são formas de determinar e controlar ${ }^{15} \mathrm{o}$ conteúdo a ser desenvolvido na escola. Tais estratégias dificultam a possibilidade de o educador desenvolver o processo ensino-aprendizagem de forma reflexiva, autônoma e criadora, mas como uma cartilha a ser seguida.

A lógica parece contrária ao que, de fato, tem ocorrido, ou seja, a escola, tendo como veículo de educação, os professores, ensinam aquilo que é exigido dos órgãos gestores e políticas públicas, quando, na verdade, deveria ser considerado aquilo que o educador promovesse como ensino autônomo.

11 Índice de Desenvolvimento da Educação Básica (Ideb) criado pelo Inep, em 2007, que busca explicitar nos sistemas escolares, dois indicadores: aprovação escolar e médias de desempenho nas avaliações.

12 Avaliação criada em 2005, pelo Ministério da Educação, realizada a cada dois anos, com a participação de estudantes de escolas públicas do $5^{\circ}$. ano e do $9^{\circ}$. ano e $3^{\circ}$. ano do Ensino Médio. A avaliação é dividida em duas provas: Língua Portuguesa e Matemática.

13 O Sistema de Avaliação da Educação Básica (Saeb) objetiva avaliar a Educação Básica por meio de dados e indicadores quantitativos.

14 Para Hypolito (1991), as transformações no mundo do trabalho determinam as avaliações institucionais e as reformas do ensino cumprem exatamente essa função avaliativa e prospectiva, a qual se trata da formação de trabalhadores, meros executores de tarefas mecânicas.

15 De acordo com Hypolito (1991), na contemporaneidade o professor vive um momento contraditório, entre o profissionalismo e a proletarização. Para o autor, a maioria dos professores possui pouco controle sobre o seu trabalho. "O oposto ao profissionalismo é a proletarização. Neste caso, além da força de trabalho ser vendida, o trabalhador não possui nenhum controle sobre os meios de produção, sobre o objeto e o processo de trabalho. Não possui autonomia, constituindo-se num trabalhador coletivo. Seu saber, ao longo do desenvolvimento do processo de trabalho, é apropriado pelo capital e incorporado ao processo de produção" (HYPOLITO, 1991, p. 13). 
Nessa perspectiva, Ball (2005) nos esclarece que, dessa forma, o aluno é visto como um cliente e, portanto, o professor está ali para atender sua "vontade", sendo treinado para ser um técnico e não um profissional capaz de refletir.

Para Ball (2005), a instauração de uma cultura de performatividade competitiva envolve uma combinação de descentralização, alvos e incentivos para produzir novos perfis institucionais. Esse processo se inspira em teorias econômicas e práticas industriais que associam o desempenho das escolas criando recompensas e punições por meio da competição entre elas, sendo o pagamento por desempenho, um bom exemplo disso.

Vale ressaltar que ao estabelecer tais padrões, enfatiza-se uma cultura extremamente competitiva entre os próprios pares em uma instituição que deveria ser um espaço privilegiado de construções coletivas. Para isso, são incutidas nos professores atitudes que fazem que eles se sintam responsáveis pelo bem-estar da instituição. Quando se estabelece uma cultura empresarial competitiva nas escolas, o ambiente coletivo é amplamente atingido (BALL, 2005). A criação de índices e indicadores das escolas, focalizando a competição e o desempenho como parâmetros de qualidade, acaba explicitando as diferenças sociais existentes em vários contextos, desconsiderando os problemas sociais onde as escolas se situam. Premia as escolas que têm melhor desempenho por fornecer indicadores que podem ser propagados na mídia.

É nesse momento que entra em cena a mídia, assumindo certa proeminência, seja por divulgar a aplicação e os resultados das avaliações em larga escala; publicizar os indicadores educacionais produzidos por tais avaliações ou comentar resultados, fomentando, assim, a inclusão do tema na agenda da Educação nacional (ESQUISANI, 2010, p. 132).

No entanto, as políticas públicas deveriam intervir na superação dos problemas a fim de promover o acesso e a permanência dos alunos na escola, conforme preconizada pela Constituição Federal ${ }^{16}$ e não simplesmente valorizar rankings, números e indicadores.

A esse mecanismo, Ball (2005) denomina de construção de "espetáculos" e "produtos", onde os índices e os resultados comparativos são usados pelos governos para "fabricar" desempenhos, por conseguinte explorar propagandas na mídia.

O Quadro 1 ilustra as diferenças entre o desenvolvimento de uma prática pedagógica reflexiva e uma prática ancorada na cultura da performatividade.

Para além desses fatores presentes, a cultura da performatividade dentro da escola retira do professor certa segurança diante de uma metodologia eficaz e cria sentimento de culpabilização diante do fracasso do aluno, à medida que o Estado propõe constantemente modos de ensinar e avaliar, por meio de diretrizes e orientativos. "As regulamentações que recaem sobre o docente não concernem somente ao quê ensinar, mas também amiúde, a como ensinar" (ENGUITA, 1991, p. 48). Para o autor, as autoridades que "governam" a escola, impõem formas de organizar turmas, modos de avaliações, conteúdos etc. Dessa maneira, o professor tem sua autonomia retirada à custa de um controle pedagógico. Vale ressaltar que a cultura da performatividade pode ocorrer tanto no campo esportivo, quanto nas diretrizes pedagógicas oficiais.

16 A Constituição Federal no capítulo III, seção I, artigo 206 preconiza: O ensino será ministrado com base nos seguintes princípios: I - igualdade de condições para o acesso e permanência na escola. 
Quadro 1: Comparativo entre prática pedagógica autônoma ${ }^{17} \mathrm{x}$ prática pedagógica controlada ${ }^{18}$ tendo como base, Enguita (1991) e Freire (2016).

\begin{tabular}{|l|l|l|}
\hline Fatores envolvidos & Prática pedagógica autônoma & Prática pedagógica controlada \\
\hline Formação acadêmica & $\begin{array}{l}\text { Tem papel preponderante em } \\
\text { uma atuação crítica-reflexiva }\end{array}$ & $\begin{array}{l}\text { Assume importância secundária } \\
\text { para um mero executor }\end{array}$ \\
\hline Avaliações e conteúdos & $\begin{array}{l}\text { Elaboradas pelo professor e } \\
\text { guiadas pela curiosidade }\end{array}$ & $\begin{array}{l}\text { Determinadas por órgãos } \\
\text { externos, baseadas na lógica do } \\
\text { mercado }\end{array}$ \\
\hline Êxito & $\begin{array}{l}\text { Conforme avança a maioria dos } \\
\text { envolvidos }\end{array}$ & $\begin{array}{l}\text { Ancorado na obtenção de } \\
\text { prêmios de um no restrito de } \\
\text { alunos e professores }\end{array}$ \\
\hline $\begin{array}{l}\text { Implicações no ambiente } \\
\text { coletivo }\end{array}$ & $\begin{array}{l}\text { O sucesso de um depende do } \\
\text { sucesso de todos }\end{array}$ & $\begin{array}{l}\text { O sucesso de alguns torna- } \\
\text { se fator de desânimo para os } \\
\text { demais }\end{array}$ \\
\hline Estratégias & $\begin{array}{l}\text { Compromisso com a aquisição } \\
\text { de aprendizagens básicas }\end{array}$ & $\begin{array}{l}\text { É preciso "propagandas", } \\
\text { criar "resultados" do ambiente } \\
\text { escolar }\end{array}$ \\
\hline
\end{tabular}

Logicamente, compreende-se, no caso da EF, algumas características da performatividade enraizadas na própria disciplina, nos modos de atuar de grande parte de professores. Segundo Daolio (2006, p. 86): "Entendemos que a educação física é uma prática cultural, com uma tradição respaldada em certos valores. (...) Sendo uma prática tradicional, ela possui características muitas vezes inconscientes para seus atores". Obviamente, pode haver uma separação entre a ação de professores que consideram boas práticas de ensino, alinhadas com o Movimento Renovador, ${ }^{19}$ fruto de formação específica, ou o "atendimento" aos rigores do desempenho. Nessa escolha, os professores devem reconhecer conscientemente o modelo pedagógico que exploram ou aquele que realmente gostariam de explorar.

Quando o professor concentra seus esforços na busca por resultados quantitativos, logicamente somente os alunos mais habilidosos (a minoria) se destacarão, à pena da maioria ficarem excluído ${ }^{20}$ ao não atenderem às exigências técnicas do esporte de alto nível. "O problema é que poucos alunos atingem os níveis esperados, ao preço da maioria

17 Por prática autônoma, compreende-se a ação docente desenvolvida com liberdade de escolha pelo professor, podendo empregar conhecimentos oriundos de uma formação sistêmica, inicial e continuada (FREIRE, 2016).

18 O controle pedagógico tem como implicações o emprego de conhecimentos no processo de ensino, que atenda aos interesses de determinada instituição ou empresa, uma atividade técnica sem obrigatoriamente uma necessidade formativa acadêmica (ENGUITA, 1991).

19 O Movimento Renovador da EF surgiu a partir do final da década de 1970, propondo novas abordagens pedagógicas, com a contribuição das Ciências Humanas, como uma possibilidade de contrapor modelos pedagógicos ancorados em perspectivas exclusivamente biológicas e tecnicista. Essas abordagens têm em comum o entendimento que as aulas de EF são espaços de desenvolvimento de conteúdos da cultura corporal de movimento (jogos, ginástica, dança, luta e esporte). No entanto, alguns estudos consideram que a prática da EF ainda é predominantemente marcada pelas aulas tradicionais com a exploração do esporte (LUTZ, TELLES e FERREIRA, 2014; CARLAN, 2012).

20 Vejamos um exemplo hipotético: Um professor de EF, que leciona em 15 turmas, tendo uma média de 500 alunos, forma uma equipe de futsal, com 12 jogadores (as) para participar de uma competição. O Restante dos 488 também se apropria das aulas e dos conteúdos como os membros dessa equipe? 
que, além de ficar alijada das aulas, passa a detestar qualquer atividade física" (DAOLIO, 2006, p. 89).

Um trabalho qualitativo, que contemple a diversidade de sujeitos e conteúdos da cultura corporal de movimento, tem o mesmo reconhecimento social?

Uma preocupação com a relativização de adoção de um modelo pedagógico é exposta por Daolio (2010, p. 13):

Ao garantir-se rigidamente a unidade da área em termos de conteúdo, pode-se desconsiderar os significados específicos de cada conteúdo em cada contexto. Em contrapartida, ao levar-se em conta a diversidade de contextos, corre-se o risco de diluição imensa dos conteúdos, chegando até mesmo ao fim da educação física escolar.

Fica esse "paradoxo" que precisa ser considerado e superado na EF escolar, sem exaurir a compreensão de que as competições escolares podem reproduzir as mesmas situações de desigualdade a que os sujeitos fazem parte. Compreendemos que os índices, números e notas são ferramentas que demonstram aspectos objetivos que nem sempre são seguidos de uma análise crítica e construtiva que possam minimizar as distâncias estruturais, que se estabelecem quando ocorrem comparações entre escolas.

Promover políticas de equidade pode produzir um ambiente coletivo mais satisfatório a todos os envolvidos, sem que a busca pela performatividade seja determinante no desenvolvimento do trabalho educacional, a pena de privilegiar poucos alunos e professores.

\section{CONSIDERAÇões FINAIS}

O esporte de alto nível influencia significativamente as aulas de EF, embora existam inúmeras iniciativas pedagógicas que tencionem com modelos reprodutivistas de esporte. Compreender o fenômeno esportivo de maneira ampla, não significa aceitar passivamente como essa prática se desenvolve predominantemente na escola.

Faz-se necessário compreender que as aulas ao atenderem pressupostos tecnicistas e tradicionais, dialogam com uma política de desempenho e aos princípios de uma performatividade, sendo características da $\mathrm{EF}$, que precisam ser relativizadas.

Seria relevante que a escola, como um todo, oportunizasse saberes que provoquem no educando o exercício da curiosidade e que o professor seja um agente de sua ação, em aproximação com o sentido de scholé, lugar do livre pensar.

Embora o esporte não deva ser negado nas aulas, é preciso explorar suas possibilidades educativas para além de uma prática reducionista, onde se prevalece a ideia de que somente a vitória é importante.

O tema em questão, carece de um número maior de construções teóricas na área da EF, que possam auxiliar professores, acadêmicos e alunos em uma recente discussão sobre o modo como atuam e como se inserem no campo pedagógico. 


\section{REFERÊNCIAS}

AFONSO, A. J. Avaliação educacional: regulação e emancipação. São Paulo: Cortez, 2009.

BALL, S. J. Profissionalismo, gerencialismo e performatividade. Cadernos de Pesquisa, v. 35, n. 126, p. 539-564, set./dez. 2005.

BARBOSA, C. L. de A. Educação Física e Filosofia: a relação necessária. Petrópolis: Editora Vozes, 2011.

BRACHT, V. Sociologia crítica do esporte: uma introdução. Ijuí: Ed. Unijuí, 2005.

. Educação física \& ciência: cenas de um casamento (in)feliz. Ijuí: Editora Unijuí, 1999.

. Educação Física e Aprendizagem social. Porto Alegre: Magister, 1992.

BRASIL. Constituição Federal de 1988. Promulgada em 5 de outubro de 1988. Disponível em: <http://www.planalto.gov.br/ccivil_03/constituicao/constituição.htm>. Acesso em: 27 fev. 2018.

CARLAN, P. O esporte como conteúdo da educação física escolar: um estudo de caso de uma prática pedagógica, 2012, 354 p. Tese (doutorado). Programa de Pós-Graduação em Educação Física, UFSC, Florianópolis, 2012.

COSTA, J. M. Esporte Escolar no Brasil: contradições e possibilidades. Revista Kinesis, v. 33, n. 1, jan./jun. 2015.

CRUZ de OLIVEIRA, R. Na "periferia" da quadra - Educação Física, cultura e sociabilidade na escola, 2010, 201 p. Tese (Doutorado em Educação Física). Curso de Educação Física, Departamento de Educação Física, Unicamp, Campinas, 2010.

DAOLIO, J. A educação física escolar como prática cultural: tensões e riscos. In: DAOLIO, J. (org.). Educação Física escolar: olhares a partir da cultura. Campinas, SP: Autores Associados, 2010, p. 5-18.

. Cultura: educação física e futebol. Campinas: Editora da Unicamp, 2006.

ENGUITA, M. F. A ambiguidade da docência: entre o profissionalismo e a proletarização. Teoria \& Educação, Porto Alegre, v. 4, p. 41-61, jan. 1991.

ESQUISANI, R. S. S. Performatividade e Educação: a política das avaliações em larga escala e a apropriação da mídia. Práxis Educativa, Ponta Grossa, v. 5, n. 2, p. 131-137, jul./dez. 2010. 
FREIRE, P. Pedagogia da Autonomia: saberes necessários à prática educativa. Rio de Janeiro: Paz e Terra, 2016.

FRIZZO, G. Os jogos escolares como mecanismos de manutenção e eliminação: uma crítica à lógica esportiva na escola. Movimento, Porto Alegre, v. 19, n. 4, p. 163-180, out./ dez. 2013.

GOMES, C. L. Lazer, trabalho e educação: relações históricas, questões contemporâneas. Belo Horizonte: Editora UFMG, 2008.

GRUNENNVALDT, J. T.; KUNZ, E. Educação Física Escolar e megaeventos esportivos: quais suas implicações?. Brasília: Em Aberto/Instituto Nacional de Estudos e Pesquisas Educacionais Anísio Teixeira, v. 26, n. 89, p. 19-32, jun. 2013.

HARVEY, D. Condição Pós-Moderna. Uma Pesquisa sobre as Origens da Mudança Cultural. São Paulo: Edições Loyola, 2008.

HYPOLITO, Á. M. Processo de trabalho na escola: algumas categorias para análise. Teoria \& Educação, v. 4, p. 3-21, 1991.

ILHA, F. R. da S.; HYPOLITO, Á. M. Esportivização da Educação Física escolar: um dispositivo e seus regimes de enunciação. Movimento, Porto Alegre, v. 22, n. 1, 173-186, jan./mar. 2016.

KIOURANIS, T. D. S. Os jogos escolares brasileiros chegam ao século XXI: reprodução ou modernização na política de esporte escolar?, 2017, 292 p. Tese (Doutorado). Programa de Pós-Graduação em Educação Física. UFPR, Curitiba, 2017.

LUTZ, T., TELLES, S. de C. C. e FERREIRA, M. S. Educação física escolar: [ainda] incertezas e indefinições. Salusvita, Bauru, v. 33, n. 2, p. 223-241, 2014.

MARCHELLI, P. S. Expansão e qualidade da Educação Básica no Brasil. Cadernos de Pesquisa, v. 40, n.140, p. 561-585, mai./ago., 2010.

MAUSS, M. Sociologia e antropologia. São Paulo: Cosac, 2003.

MINAYO, M. C. de S. Ciência, técnica e arte: o desafio da pesquisa social. In: MINAYO, M. C. de S. (org.). Pesquisa Social. Petrópolis, RJ: Vozes, 1994.

MORMUL, N. M.; MACHADO, M. C. G. Rui Barbosa e a educação brasileira: os pareceres de 1882. Cadernos de História da Educação, v. 12, n. 1, p. 277-294, jan./jun. 2013.

SEVERINO, A. Metodologia Trabalho Científico. São Paulo: Cortez, 2007. 
SOUZA, L. C. de; REZENDE, L. de Q.; OLIVEIRA, R. T. Educação Física Escolar, ou as determinações do esporte e dos jogos escolares?. Anais. XVII Congresso Brasileiro de Ciências do Esporte e IV Congresso Internacional de Ciências do Esporte. Porto Alegre, 2011. Disponível em: http://www.rbceonline.org/congressos/index.php/XVII. Acesso em: 4 de novembro de 2017.

TUBINO, M. J. G. Estudos brasileiros sobre o esporte: ênfase no esporte-educação. Maringá: Eduem, 2010.

\section{DAdOS DO AUTOR:}

\section{JEDERSON GaRbin TENóRIO}

Mestre em Ciências do Movimento Humano. Professor da Rede de Ensino de Mato Grosso/ MT-Brasil. jederson.21@hotmail.com

Submetido em: 4-6-2019

Aceito em: 24-3-2020 